ENCYCLOPÉDIE Encyclopédie berbère

BERBERE

32 | 2010

32 | Mgild - Mzab

\title{
Musiques touarègues : La poésie chantée
}

H. Claudot-Hawad

\section{OpenEdition}

Journals

Édition électronique

URL : https://journals.openedition.org/encyclopedieberbere/666

DOI : 10.4000/encyclopedieberbere.666

ISSN : 2262-7197

\section{Éditeur}

Peeters Publishers

\section{Édition imprimée}

Date de publication : 31 décembre 2010

Pagination : $5139-5144$

ISBN : 978-90-429-2369-0

ISSN : 1015-7344

\section{Référence électronique}

H. Claudot-Hawad, « Musiques touarègues : La poésie chantée », Encyclopédie berbère [En ligne], 32 2010, document M147b, mis en ligne le 11 novembre 2020, consulté le 17 février 2022. URL : http:// journals.openedition.org/encyclopedieberbere/666 ; DOI : https://doi.org/10.4000/ encyclopedieberbere.666

Ce document a été généré automatiquement le 17 février 2022.

(c) Tous droits réservés 


\title{
Musiques touarègues : La poésie chantée
}

\author{
H. Claudot-Hawad
}

1 Chez les Touaregs, la poésie chantée (ezale en tamajăq) est imaginée métaphoriquement comme un arbre qui possède ses racines, son tronc, ses branches et ses rameaux multiples.

2 Les «branches », izlan", représentent la poésie « classique », chantée et accompagnée à la vièle monocorde. Cet instrument est l'apanage des femmes nobles ou, dans certaines régions, des femmes artisanes. D'inspiration épique, le thème, la forme et le rythme des ižlan obéissent à des règles strictes, illustrant les valeurs du monde touareg ancien où sont chantés dans un rapport de symbiose l'honneur guerrier, l'amour courtois et le nomadisme qui obéit aux lois de l'univers (voir: Ch. de Foucauld, Poésies touarègues, Paris, 1925-1930, 2 t. et Ch. Mohamed et K. Prasse, Poèmes touaregs de l'Ayr, Copenhague, Museum Tusculanum Press, 1989, 2 t.).

3 Les poèmes déclamés, tishiwey ou tisiwey, apparaissent comme une production plus autonome par rapport à la morale et aux valeurs établies de la société. Ils retracent un parcours individuel qui n'est pas forcément exemplaire. Ces poésies sont énoncées sur un rythme très rapide, performance à la musicalité heurtée que l'on peut qualifier de poésie d'apnée. Elles sont ponctuées par les cris d'émotion et les réactions de l'auditoire. En fait, les tishiwey peuvent être considérés comme l'étape qui précède la création des izlan. En effet, c'est lorsque ces poésies étaient jugées représentatives de l'idéal touareg qu'elles étaient mises en musique, accompagnées à la vièle, s'intégrant alors au patrimoine collectif.

4 Au début du XX $\mathrm{X}^{\mathrm{e}}$ siècle, après le choc de la défaite des Touaregs contre l'armée coloniale française, le souffle épique qui nourrissait la poésie classique s'étiole. Par contre, la composition des tishiwey se poursuit et de nouveaux modes d'expression naissent en se dégageant des registres anciens. Ainsi apparaissent et s'imposent des thèmes, des styles poétiques, des accompagnements musicaux et des langages nouveaux.

5 A l'est, par exemple, le poète Ekhalawey, originaire de l'Air, est une figure célèbre et moderne des tishiwey. Dans son registre d'images, il innove et provoque en juxtaposant 
à l'imaginaire poétique classique de l'honneur guerrier les empreintes peu glorieuses du nouveau monde. Il décrit la prison, l'humiliation de la société touarègue face à l'ordre colonial, l'affrontement avec l'administration et l'armée françaises, et montre l'incompatibilité entre ces deux univers présentés en jeu de miroirs.

Dans les années 1940, tandis que la domination s'est enracinée, d'autres formes de résistance individuelles fleurissent: c'est l'époque des "bandits d'honneur" marquée par des personnages célèbres comme Alla ag Albachar dans l'Adagh et Akhmad Egeraw dans l'Aïr. Leurs exploits fournissent un nouvel élan au registre épique, bien que les actions d'éclat de ces héros, transformés en maquisards isolés affrontant l'armée à coup d'embuscades, aient changé de forme. Cette poésie est influencée également par le répertoire des chants de défi, les isebelbilen, sorte de glossolalie d'action que les guerriers improvisent avant le combat pour intimider l'adversaire.

7 Contraignant la société à sortir de sa torpeur, les voix féminines, enfin, substituent aux genres épiques et lyriques une littérature satirique, défensive et critique. Les "branches" de la poésie classique sont coupées et deviennent littéralement des "fouets", ilegwan, destinés à flageller la communauté pour la faire réagir. Ces poèmes chantés sont rythmés et s'interprètent accompagnés du tambour. La tendé, nom de cet instrument formé d'un mortier sur lequel est tendue une peau de chèvre, désigne également l'assemblée où l'on en joue et le répertoire musical et littéraire correspondant. Dans une tende, les chanteuses sont regroupées au centre de la scène, formant un cercle compact autour duquel défilent les chameliers au pas cadencé de leurs montures. Cette manifestation s'oppose à la cour poétique réunie autour d'une ou de plusieurs joueuses de violon, symbole du jugement de l'honneur selon les critères anciens. Tout en conservant comme référence les valeurs guerrières touarègues, les ilegwan intègrent la réalité présente et rompent avec les images idéalisées d'un passé révolu. Les compositions de ces chants sont constamment remodelées et réappropriées par de nouveaux interprètes qui, chacun, y ajoutent des passages personnels, si bien que l'auteur initial est souvent oublié.

8 En 1963 la révolte de l'Adagh éclate, réprimée dans un bain de sang par l'armée malienne. De cette région sinistrée, s'exileront des familles entières, à la suite des ishumar, terme formé à partir du mot français "chômeur", partis à la recherche d'un travail dans le nord-est du pays touareg, c'est-à-dire l'Ahaggar et l'Ajjer, désormais rattachés à l'Algérie et à la Libye. Progressivement, ce mouvement constamment alimenté par des flux humains venus de toutes les régions touarègues affirme sa volonté de forger une résistance moderne et marginale contre un système qui vient de précipiter la ruine économique de la société.

9 Alors que les chants sur la rébellion de l'Adagh n'ont pas dépassé la région, les poèmes des exilés - décrivant la dureté du quotidien, les humiliations, la confrontation avec la logique des Etats, mais aussi l'affirmation de soi - circulent dans tout le pays touareg. Aux critiques féminines qui les accusent d'abandonner leur famille sans protection, les ishumar opposent un nouveau portrait d'homme touareg aux prises avec les Etats: individualiste, marginal, insaisissable, maître de son espace, mais étrange et choquant pour la société à qui est renvoyé un reflet d'elle-même privé de l'honneur ancien, qu'elle peine à accepter :

Je porte une vieille outre

en bandoulière

et des sandales taillées

dans les pneus de vos land-rover. 
Voilà mon équipage !

Ma route est tracée

d'un coup de talon en arrière

et d'un coup en avant ${ }^{2}$.

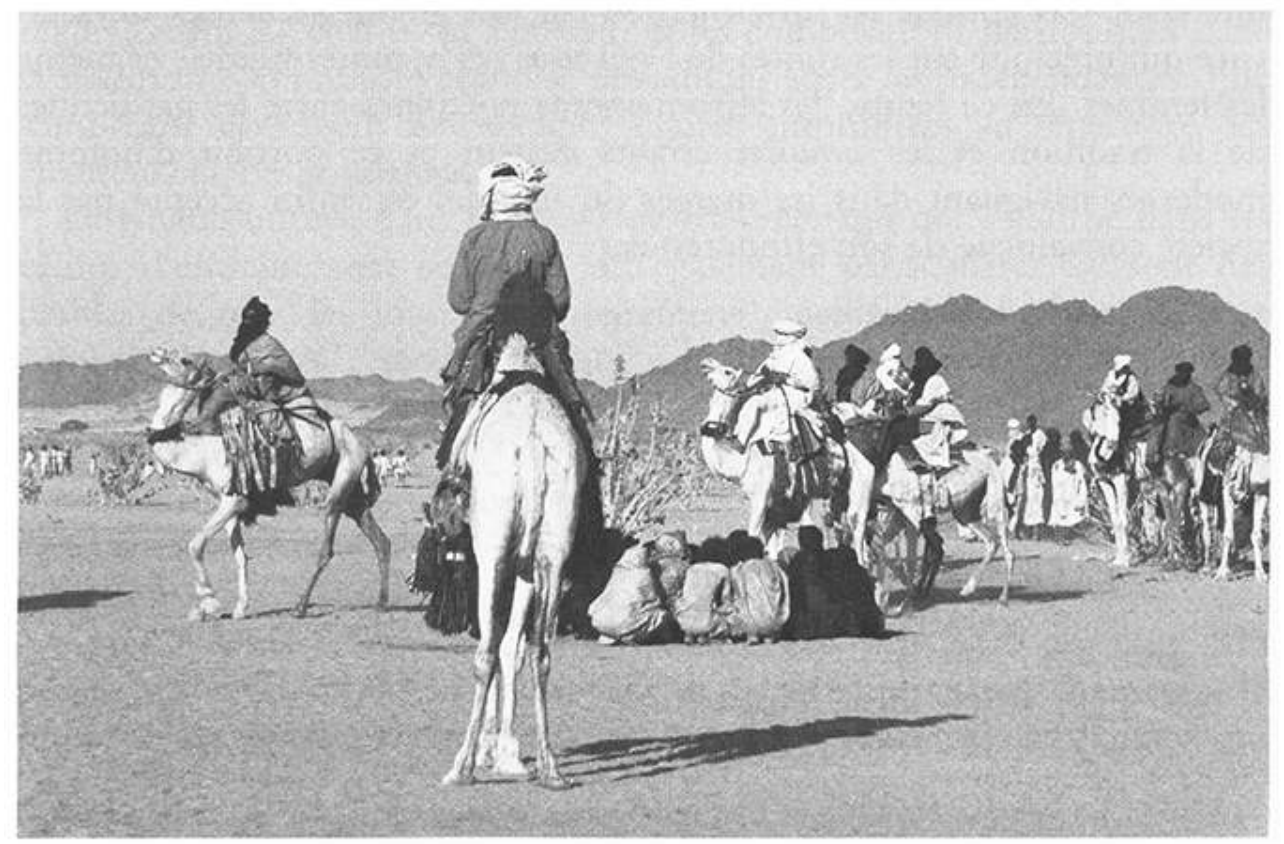

ILEgWAN, AHAggaR, 1984.

Cliché H. Claudot-Hawad.

Divers genres littéraires naissent de cette dernière vague qui fait concurrence aux ilegwan : poésie "libre", échappant aux règles strictes de la prosodie et aux thèmes qui ponctuent les œuvres classiques. Dans cet éventail de styles, la poésie reste prépondérante. Elle est le plus souvent composée oralement et chantée, suivant l'inspiration de chaque auteur, sur un thème mélodique sans accompagnement instrumental ce qui ne favorise pas son appropriation collective.

11 Dans les années 1980, le régime libyen ouvre les portes de ses camps d'entrainement militaire aux Touaregs qu'il appelle à « libérer leur pays », formulation ambiguë dont les limites sont rapidement découvertes par les intéressés. Cet épisode est suivi en 1984 par une grande sécheresse dévastatrice qui précipite sur les routes de l'exil tous les hommes valides, et même les femmes. En ce temps, les affrontements poétiques entre les gardiennes de la tradition et les ishumar errants cessent et ce portrait d'homme moderne, naviguant dans les marges du monde, est enfin accepté par la société convaincue de son effondrement :

Sac marin, kalachnikov

sur les épaules

la voie c'est teshumara

la vitesse, Toyota

le chèche, quinze mètres sur ma tête

ma tête, une cocotte minute

Attrapez-là

et ma cervelle explosera

entre vos mains

(Adam ag Albaka, Aïr) $^{3}$ 
A ce tableau, répond la voix corrosive de la chanteuse de tendé:

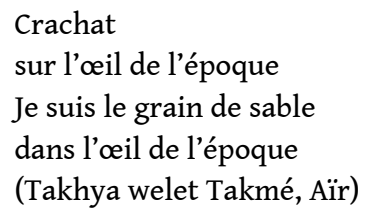

Va alors se développer un vaste répertoire de poèmes chantés et accompagnés avec des instruments modernes comme la guitare électrique. Ces complaintes, grâce au magnétophone, se répandent comme une trânée de poudre à travers les tentes touarègues et les camps de réfugiés, de la Libye à la Mauritanie. Les textes chantent l'amour et la nostalgie du pays et de la nation, la volonté farouche de les reconstruire, la dureté de l'exil, le sacrifice nécessaire qui consiste à «troquer son sang contre le savoir militaire ", la souffrance de laisser en arrière les vieillards, les femmes et les enfants en proie à "la domination qui blesse l'âme $»^{4}$. La naissance de plusieurs orchestres comme Takrast $n$ tinarewen ("Construction des déserts"), Takrast $n$ akal ("Construction du pays") ou Tagast ("Protection") va contribuer à la production et à la diffusion de ces poésies des ishumar appelées tishamurén.

La mélodie, en rupture avec les registres anciens, est née quelques années auparavant du croisement de plusieurs influences: d'abord les rythmes des chants de transe sahéliens, héritage commun aux Touaregs, Peuls et Son-ghay; ensuite la musique de tahardant (voir Ahardin*, EB III, 1986), guitare d'accompagnement utilisée dans la région du fleuve Niger par les "artisans de la parole" et dont le rythme est souligné par des battements de mains; enfin les chants du Polisario et les compositions patriotiques dans la tradition communiste chinoise introduites après les indépendances. Elle s'imprègne également de certaines figures empruntées au répertoire des chanteurs arabes soudanais.

La langue utilisée dans la poésie des ishumar qui ont séjourné dans les camps d'entraînement en Libye est également particulière. Ce sont des paroles de tous les jours, volontairement émaillées de mots considérés comme "branchés", modernes, qui sont des emprunts à l'arabe et plus rarement au français. Dans ces poèmes de l'exil, les divers parlers de la langue touarègue - tamashăq, tamajăq, tamahăq - sont souvent mêlés, avec cependant une prédominance de la langue de l'Adagh, creuset d'origine de cette poésie.

Après le soulèvement armé de 1990 au Niger et au Mali qui dure près de six ans et la venue en Europe de certains combattants chanteurs, la musique des ishumar est prise en main par des producteurs occidentaux qui lancent certains groupes sur la scène artistique internationale. De répertoire engagé produit par un mouvement de résistance contre les Etats qui étouffent la société touarègue, les chants des ishumar se muent en "musique du monde » et se plient aux goûts musicaux mondialisées qui estompent leur originalité première et l'apparentent rapidement à un produit de variétés utilisé comme musique d'ambiance. 


\section{NOTES}

1. NDLR : sing. : azel. «branche d'arbre ou d'arbuste quelconque [...]. Par ext. air de violon...», cf. Ch. de Foucauld, Dictionnaire touareg-français, t. IV, Paris, 1952, p. 1955) et Karl-G. Prasse et al., Dictionnaire touareg-français, Copenhague, 2003, p. 915. L'association entre les deux significations «branche » et « air de violon » est commune à l'ensemble du domaine touareg et doit donc être considérée comme fondamentale. On rapprochera aussi ce mot touareg du berbère Nord izli/izlan (sans pharyngalisation $\mathrm{du} / \mathrm{z} /$ ), « poème court, distique » (kabyle, Maroc...), qui est sans doute le terme commun berbère pour désigner le vers poétique de base. Ce couple azel/izli mériterait certainement une étude lexico-sémantique approfondie.

2. Cité et traduit par HAWAD, in "La teshumara, antidote de l'Etat", Touaregs, Exil et résistance, Revue du Monde Musulman et de la Méditerranée n 57, Edisud, Aix-en-Provence, 1990.

3. in opus cité.

4. Voir CLAUDOT-HAWAD $\mathrm{H}$. et HAWAD, "Tourne-tête, le pays déchiqueté» (Taqanéghaf, akal yemixawén). Anthologie des chants et poèmes touaregs de résistance, 1980-1995, La Bouilladisse, Editions Amara, 1994.

\section{INDEX}

Mots-clés : Chant, Ethnologie, Ethnographie, Littérature, Mali, Niger, Poésie, Sahara, Sahel, Touareg 